\title{
Development and Evaluation of Immune Boosters Based Health Plus for HIV/AIDS
}

\author{
Pa. Raajeswari ${ }^{*}$ and N. Bhooma ${ }^{2}$ \\ ${ }^{1}$ Assistant Professor, Department of Food Science and Nutrition, Avinashilingam Institute for Homescience and \\ Higher Education for Women , Coimbatore-43, India; raajraaeshwari@gmail.com \\ 2Professor, Department of Food Science and Nutrition, Arinashilirjam Institute for Home Science and Higher \\ Education forwomen, Coimbatore-43; India.
}

\begin{abstract}
An ideal food for prevention and correction of nutritional inadequacies should be of high nutritive value, acceptable, readily available at low price, familiar to the community and have good tolerance both in good health and illness. Development of supplements using low cost locally available indigenous foods familiar to the community, especially women, has been one of the strategies proven to be effective in improving the health status of the community. Keeping this in view, the present study was undertaken with the main objective to identify the locally available foods rich in immune boosters, modulators and regulators, and to formulate different five health mixes coded as HMI, HMII, HM III, HM IV and HM V. To identify the best combination and proportion of ingredients, six variations were formulated from each health mix making the total to thirty. All the thirty variations of the health mixes were given different code numbers. By applying five point rating scale and DMR test, the highly acceptable mix was selected. The results showed that among the best varieties from each health mix, variations from each health mix variation 5 of health mix $V$ got the highest score in taste and colour, maximum nutrient content, minimum moisture content and peroxide value and less total bacterial count and hence variations of health mix $\mathrm{V}$ was adjusted to be the best and named as HEALTH PLUS. The findings of the study revealed that the ingredients namely wheat, soy flour, wheat germ, tomato, beet root, sun flower seeds, and jaggery which are available at our doorsteps are foods rich in immune boosters, modulators and regulatory to improve the immune level of the HIV positive women.
\end{abstract}

Keywords: Bamboo Seed Flour, Central Composite Rotatable Design, Pasting Properties, Rapid Visco Analyser, Standard 1 Profile

\section{Introduction}

The relationship between nutrition and HIV is a vicious cycle, similar to the relationship between nutrition and other infections. Poor nutritional status is one of the major complications of HIV and a significant factor in full-blown AIDS. A well-balanced diet and micronutrient supplementation seem to be warranted to ensure optimal health and survival particularly in HIV-infected women [1]. Provision of simple, inexpensive micronutrient supplements as an adjunct to Highly Reactive Anti Retroviral Therapy (HAART) may have several cellular and clinical benefits, such as reduction in mitochondrial toxicity,

*Author for correspondence oxidative stress and improvement in immune reconstitution [2]. An ideal food for prevention and correction of nutritional inadequacies should be of high nutritive value, acceptable, readily available at low price, familiar to the community and have good tolerance both in good health and illness [3], [4]. Development of supplements using low cost locally available indigenous foods familiar to the community especially women, has been one of the strategies proven to be effective in improving the health status of the community [5]. Hence the present study was undertaken to develop and evaluate a immune boosters based health mix for feeding HIV positive women. 


\section{Materials and Methods}

\subsection{Formulation and Standardisation of Health Mixes}

\subsubsection{Identification and Selection of Foods Rich in Immune Boosters, Modulators and Regulators}

Food supplementation is one of the effective ways of improving the health status of affected HIV/AIDS positive women by means of increasing the CD4 cell count and hence decreasing the chances of opportunistic infections. Keeping all these points in mind the investigator formulated different health mixes consisting of food immune boosters, modulators and regulators chosen from five food groups Foods namely wheat, corn, soy, soy protein isolate, wheat germ, tomato, beetroot, carrot, amla, garlic, onion, peanuts, sunflower seeds and jaggery were identified as foods that improve immune function. The identified food ingredients rich in immune boosters, modulators and regulators are given in plate 1. The identified foods along with their functional principles responsible for improving the immune system in People Living With HIV/AIDS is given in Table 1..

\subsubsection{Formulation and Evaluation of Different Health Mixes}

\subsubsection{Formulation of Different Health Mixes}

The selected ingredients (indicated in the Table 1) were processed and formulated into different health mixes. The preliminary preparation of ingredients such as cutting, peeling, washing and sprouting were adopted to enhance the palatability and acceptability of the food ingredients.

Whole wheat was germinated for 24 hours to increase the nutrient content. Corn flour, soy flour, wheat germ and soy protein isolate were purchased as such to incorporate in the health mix. Carrot, beetroot and amla were thoroughly washed, scrapped and shade dried for a week. Tomato was thoroughly washed and cut into small pieces. Fresh thulasi leaves were obtained from the farm. Edible portions of onion and garlic werechopped into small pieces.

Clean sunflower seeds and peanuts were used. The above mentioned ingredients were allowed to shade dry in a plastic sheet and were turned off frequently at regular intervals to ensure proper drying. The dried ingredients were individually roasted at suitable temperature to enhance the aroma and shelf-life. Roasting technique was used in the processing of cereals, pulses and oil seeds [6] to improve availability. The details regarding the pre-treatment and processing techniques followed for the different food ingredients is outlined in the Figure 1. The processed ingredients were ground into fine powder (Plate 4) and stored in air tight containers separately. Five Health Mixes (HM) were prepared using the processed food ingredients and coded as HM I, HM II, HM III, HM IV, and HM V. To identify the best combination and proportion of ingredients six variations were formulated from each health mix making the total to thirty. Finally thirty formulations were evolved and the detail of the formulations is presented in Tables 2 to 6 .

\subsubsection{Acceptability Trial}

The formulated health mixes were intended for feeding HIV positive women to improve their nutritional and health status. Organoleptic evaluation of the thirty variations was carried out by 10 panels of judges. All the thirty variations of the health mixes were given different code numbers. Each panel of judges were given $25 \mathrm{gms}$ of health mixes in the form of ladoos, prepared using $25 \mathrm{gms}$ of health mixes with hot water to assess the quality factors such as colour, flavour, texture and taste. The overall acceptability was assessed using a five point rating scale.

\subsubsection{Shelf Life Assay of the Health Mixes}

The health mixes were packed in heat sealed low density polyethylene bags (200 gauges) and stored at room temperature between 27 and $35^{\circ} \mathrm{C}$ with relative humidity of 70-85 per cent for three months for their keeping quality evaluation. The shelf life of the health mixes was assessed through organoleptic parameters, moisture content [7], peroxide value (Sadasivam, 1997) and total bacterial count by pour plate method in comparison with the fresh formulations.

\section{Results and Discussion}

\subsubsection{Organoleptic Evaluation of Health Mixes}

Five health mixes with six variations each making the total of 30 variations were developed and subjected to organoleptic evaluation and the scores are presented in Table 7. 
Table 1. The identified foods along with their functional principles

\begin{tabular}{|c|c|c|}
\hline S.No & $\begin{array}{c}\text { Food Immune Boosters, } \\
\text { Modulators and } \\
\text { Regulators } \\
\end{array}$ & Functional Principles \\
\hline 1 & Wheat & $\begin{array}{l}\text { Minerals, antioxidants (tocotrienols, selenium, phenolic acid and phytic acid), lignans, } \\
\text { phytonutrients, water - soluble, fat soluble vitamins }\end{array}$ \\
\hline 2 & Corn & Cryptoxanthian, thiamin, pantothenic acid, folate and iron \\
\hline 3 & Soy & High quality protein, isoflavones, aminoacids, terpernoids, iron, calcium, and B-vitamins \\
\hline 4 & Soya protein isolate & High quality protein, isoflavones, aminoacids, terpernoids, iron, calcium, and B-vitamins \\
\hline 5 & Wheat germ & $\begin{array}{l}\text { Antioxidants-isoflavones, peptides, carbohydrates, fatty acids, coenzymes, amines, poly } \\
\text { amines, saponins, terpenoids. }\end{array}$ \\
\hline 6 & Tomato & Vitamin - A, C, E, zinc and lycopene, phosphorus, sulphur, potassium and zinc \\
\hline 7 & Beetroot & Vitamin A,C, E, di-o-gallolyl-d glucose, digalleo acid, betaine, choline, folic acid and iodine \\
\hline 8 & Carrot & Beta-carotene, vitamin-K, E and $\mathrm{C}$ \\
\hline 9 & Amla & Vitamin-C, calcium, phosphorus and iron \\
\hline 10 & Thulasi & Flavonoids, eugenol, iron, calcium, vitamin-A and vitamin-K \\
\hline 11 & Garlic & $\begin{array}{l}\text { Minerals, antioxidants (tocotrieonols, selenium, phenolic acid and phytic acid), lignans, } \\
\text { phytonutrients, water soluble and fat soluble vitamins. }\end{array}$ \\
\hline 12 & Onion & $\begin{array}{l}\text { Antioxidants-isoflavones, peptides, carbohydrates, fatty acids, coenzymes, amines, poly } \\
\text { amines, saponins and terpenoids. }\end{array}$ \\
\hline 13 & Peanuts & Unsaturated fats, protein, fiber, vitamin - E, selenium, zinc, folate, iron and phytochemicals. \\
\hline 14 & Sunflower seeds & Unsaturated fats, protein, fiber, vitamin - E, selenium, zinc, folate, iron and phytochemicals. \\
\hline 15 & Jaggery & Medicinal sugar- minerals, iron, vitamins mainly manganese and selenium \\
\hline
\end{tabular}

Table 2. Health mix I

\begin{tabular}{|l|l|l|l|l|l|l|l|}
\hline \multirow{2}{*}{ S.No. } & \multirow{2}{*}{ Ingredients } & \multicolumn{6}{|c|}{ Variations (g) } \\
\cline { 3 - 8 } & & $\mathbf{1}$ & $\mathbf{2}$ & $\mathbf{3}$ & $\mathbf{4}$ & $\mathbf{5}$ & $\mathbf{6}$ \\
\hline & & & & & & & \\
2. & Wheat & 20 & 10 & 30 & 25 & 20 & 10 \\
3. & Soy flour & 20 & 10 & 30 & 25 & 20 & 10 \\
4. & Beetroot & 20 & 30 & 10 & 15 & 10 & 20 \\
5. & Tomato & 20 & 30 & 10 & 15 & 10 & 20 \\
6. & Sunflower seeds & 10 & 10 & 10 & 10 & 20 & 20 \\
\hline
\end{tabular}

Table 3. Health mix II

\begin{tabular}{|l|l|l|l|l|l|l|l|}
\hline \multirow{2}{*}{ S.No. } & \multirow{2}{*}{ Ingredients } & \multicolumn{6}{|c|}{ Variations (g) } \\
\cline { 3 - 7 } & & $\mathbf{1}$ & $\mathbf{2}$ & $\mathbf{3}$ & $\mathbf{4}$ & $\mathbf{5}$ & $\mathbf{6}$ \\
\hline & & & & & & & \\
1. & Wheat & 20 & 25 & 30 & 20 & 30 & 10 \\
2. & Soy protein isolate & 20 & 25 & 30 & 20 & 30 & 10 \\
3. & Corn flour & 10 & 10 & 10 & 15 & 5 & 20 \\
4. & Thulasi & 15 & 10 & 10 & 15 & 5 & 20 \\
5. & Carrot & 15 & 10 & 10 & 15 & 10 & 20 \\
6. & Jaggery & 20 & 20 & 10 & 15 & 20 & 20 \\
\hline
\end{tabular}

Table 4. Health mix III

\begin{tabular}{|l|l|l|l|l|l|l|l|}
\hline \multirow{2}{*}{ S.No. } & \multirow{2}{*}{ Ingredients } & \multicolumn{7}{|c|}{ Variations $(\mathbf{g})$} \\
\cline { 3 - 7 } & & $\mathbf{1}$ & $\mathbf{2}$ & $\mathbf{3}$ & $\mathbf{4}$ & $\mathbf{5}$ & $\mathbf{6}$ \\
\hline & & & & & & \\
1. & Wheat & 20 & 15 & 25 & 10 & 15 & 20 \\
2. & Soy flour & 20 & 20 & 15 & 20 & 15 & 20 \\
3. & Corn flour & 10 & 15 & 20 & 20 & 15 & 20 \\
4. & Thulasi & 2.5 & 2 & 5 & 5 & 10 & 5 \\
5. & Carrot & 5 & 2.5 & 2.5 & 5 & 10 & 5 \\
6. & Peanuts & 5 & 7.5 & 2.5 & 12.5 & 10 & 10 \\
7. & Sunflower seeds & 5 & 6 & 2.5 & 5 & 5 & 5 \\
8. & Amla & 2.5 & 2 & 5 & 2.5 & 5 & 5 \\
9. & Jaggery & 30 & 30 & 22.5 & 20 & 15 & 10 \\
\hline
\end{tabular}

The proportions were transformed into angles by applying sinx and angular transformation to make the variable (proportion) into a normal variable. Analysis of variance technique was then employed to determine the priority of the groups. The $\mathrm{F}$ test turned out to be non-significant, since the group priority is a necessity in the follow-up study where the supplementation aspect has to go on with a particular group. 
Table 5. Health mix IV

\begin{tabular}{|l|l|l|l|l|l|l|l|}
\hline \multirow{2}{*}{ S.No. } & \multirow{2}{*}{ Ingredients } & \multicolumn{6}{|c|}{ Variations (g) } \\
\cline { 3 - 8 } & & $\mathbf{1}$ & $\mathbf{2}$ & $\mathbf{3}$ & $\mathbf{4}$ & $\mathbf{5}$ & $\mathbf{6}$ \\
\hline \multirow{2}{*}{1.} & Wheat & 20 & 15 & 10 & 5 & 10 & 15 \\
2. & Soy flour & 15 & 20 & 15 & 10 & 10 & 5 \\
3. & Beet root & 10 & 5 & 10 & 15 & 10 & 15 \\
4. & Sunflower seeds & 5 & 10 & 15 & 20 & 15 & 20 \\
5. & Garlic & 15 & 10 & 5 & 10 & 15 & 20 \\
6. & Onion & 15 & 10 & 5 & 10 & 15 & 10 \\
7. & Tomato & 10 & 15 & 20 & 15 & 10 & 5 \\
8. & Carrot & 10 & 15 & 20 & 15 & 15 & 10 \\
\hline
\end{tabular}

Table 6. Health mix V

\begin{tabular}{|l|l|l|l|l|l|l|l|}
\hline \multirow{2}{*}{ S.No. } & \multirow{2}{*}{ Ingredients } & \multicolumn{6}{|c|}{ Variations (g) } \\
\cline { 3 - 8 } & & $\mathbf{1}$ & $\mathbf{2}$ & $\mathbf{3}$ & $\mathbf{4}$ & $\mathbf{5}$ & $\mathbf{6}$ \\
\hline & & & & & & \\
1. & Wheat & 15 & 15 & 10 & 20 & 15 & 15 \\
2. & Soy flour & 20 & 10 & 20 & 20 & 15 & 5 \\
3. & Wheat germ & 15 & 20 & 20 & 15 & 15 & 15 \\
4. & Beetroot & 15 & 20 & 15 & 15 & 15 & 5 \\
5. & Tomato & 15 & 15 & 20 & 10 & 15 & 20 \\
6. & Sunflower seeds & 15 & 10 & 15 & 10 & 10 & 20 \\
7. & Jaggery & 5 & 10 & 10 & 10 & 15 & 20 \\
\hline
\end{tabular}

Therefore the DMR test was applied for the same data, where the GP again turned to be not being a significantly different one. Based on the inferences, taking the variables under analysis as a robust free variable the Fried Man's two- way analysis of the variance taking the group as the treatment and experimental individuals as conditions, has been thought as the correct methodology and the results are as follows. As far as health mix I is concerned variation 1 obtained the scores 2.3, 3.2, 3.2, 3 for the characteristics colour, flavour, texture and taste respectively, with the overall acceptability score of 11.7 out of the maximum score 20 . Similarly variation 2 received the scores $1.4,3$, 4.1 and 2.7 for the various characteristics with the overall acceptability score of 11.2. Variation 3 obtained 3.5, 3.6, 3.6, 3.7 for the various characteristics with the overall acceptability score of 14.4 out of the maximum score of 20 . Variation 4 obtained 3.9 for colour out of 5, 2.8 for flavour, 4.3 for texture and 3.8 for taste, with the maximum overall acceptability score of 14.8 . Variation 5 obtained 3.8 for colour, 3.1 for flavour, 3.4 for texture and 3.6 for taste with the overall acceptability score of 14.0. Variation 6 obtained
1.9 for colour, 3.1 for flavour, 3.6 for texture and 3.4 for taste with the overall acceptability score of 12 out of the maximum score 20. In health mix II, variation 1 secured the scores 3, 2.5, 3 and 3.1 for the various characteristics with the overall acceptability score of 11.6 , variation 2 obtained 2.6, 2.8, 2.9 and 2.1 for the characteristics with the overall acceptability score of 10.4 out of the maximum score 20. Variation 3 obtained the scores 2.9, 4, 3.9 and 3.3 for characteristics such as colour, flavour, texture and taste respectively with the overall acceptability score of 14.1 out of the maximum score 20. Variation 4 and 5 received 2.7, 2.4 for colour 3.2, 3.4 for flavour $4,3.4$ for texture and 3.3, 3.1 for taste with the overall acceptability scores of 9.4 and 12.3 respectively. Variation 6 obtained 2.5 for colour out of 5, 3 for flavour, 3.1 for texture and 3.2 for taste, with the overall acceptability score of 11.8 .

As far as health mix III is concerned variation 1 obtained scores 2, 3.2, 3.3, 3.1 for the characteristics colour, flavour, texture and taste respectively, with the overall acceptability score of 11.6 out of the maximum score 20. Similarly variation 2 received the scores 1.2, $3.2,3.3$ and 3.1 for the various characteristics with the overall acceptability score of 9.9. Variation 3 obtained 3.6, 3.5, 2.6, 2.7 for these characteristics with the overall acceptability score of 13.4 out of the maximum score of 20. Variation 4 obtained 2.8 for colour out of $5,3.5$ for flavour, 4 for texture and 2.2 for taste, with the maximum overall acceptability score of 12.5. Among the six, variations 5 and 6 received 2.5, 2.7 for colour, 3, 3.1 for flavour, 3.5, 3.9 for texture and 2.7, 2.9 for taste with the overall acceptability score of 11.7 and 12.6 respectively.

In health mix IV, variation 1 received the scores 2.3, 2.1, 3.1 and 2 for the various characteristics with the overall acceptability score of 9.5. Variation 2 obtained 3.8, 3.6, 3.1 and 2.6 for the characteristics with the overall acceptability maximum score of 13.1 out of the maximum score 20. Variation 3 obtained scores 3.3, 2.1, 3.2 and 2.6 for characteristics such as colour, flavour, texture and taste respectively with the overall acceptability score of 11.2 out of the maximum score 20. Variation 4 and 5 received 3, 3.4 for colour; 2.8, 2.6 for flavour; 3, 4 for texture and 2.2, 3 for taste with the overall acceptability scores of 11 and 13 respectively. Variation 6 obtained 3.1 for colour out of 5, 3.4 for flavour, 2.9 for texture and 2.6 for taste, with the overall acceptability score of 12 . As far as health mix $\mathrm{V}$ is concerned variation 1 obtained scores 3.9, 3.5, 3.6, 3.7, 3.1 for the characteristics colour, flavour, texture and taste respectively, with the overall 
Table 7. Organoleptic evaluation of health mixes (Maximum Score: 20)

\begin{tabular}{|c|c|c|c|c|c|}
\hline $\begin{array}{c}\text { Variations } \\
(5) \\
\end{array}$ & $\begin{array}{c}\text { Colour } \\
(5) \\
\end{array}$ & $\begin{array}{c}\text { Flavour } \\
(5) \\
\end{array}$ & $\begin{array}{c}\text { Texture } \\
(5)\end{array}$ & $\begin{array}{l}\text { Taste } \\
(5) \\
\end{array}$ & Overall Acceptability (20) \\
\hline \multicolumn{6}{|c|}{ Health Mix I } \\
\hline 1 & 2.3 & 3.2 & 3.2 & 3 & 11.7 \\
\hline 2 & 1.4 & 3 & 4.1 & 2.7 & 11.2 \\
\hline 3 & 3.5 & 3.6 & 3.6 & 3.7 & 14.4 \\
\hline 4 & 3.9 & 2.8 & 4.3 & 3.8 & 14.8 \\
\hline 5 & 3.8 & 3.1 & 3.4 & 3.6 & 14.0 \\
\hline 6 & 1.9 & 3.1 & 3.6 & 3.4 & 12 \\
\hline \multicolumn{6}{|c|}{ Health Mix II } \\
\hline 1 & 3 & 2.5 & 3 & 3.1 & 11.6 \\
\hline 2 & 2.6 & 2.8 & 2.9 & 2.1 & 10.4 \\
\hline 3 & 2.9 & 4 & 3.9 & 3.3 & 14.1 \\
\hline 4 & 2.7 & 3.2 & 4 & 3.3 & 9.4 \\
\hline 5 & 2.4 & 3.4 & 3.4 & 3.1 & 12.3 \\
\hline 6 & 2.5 & 3 & 3.1 & 3.2 & 11.8 \\
\hline \multicolumn{6}{|c|}{ Health Mix III } \\
\hline 1 & 2 & 3.2 & 3.3 & 3.1 & 11.6 \\
\hline 2 & 1.2 & 2.5 & 3.3 & 2.9 & 9.9 \\
\hline 3 & 3.6 & 3.5 & 2.6 & 2.7 & 13.4 \\
\hline 4 & 2.8 & 3.5 & 4 & 2.2 & 12.5 \\
\hline 5 & 2.5 & 3 & 3.5 & 2.7 & 11.7 \\
\hline 6 & 2.7 & 3.1 & 3.9 & 2.9 & 12.6 \\
\hline \multicolumn{6}{|c|}{ Health Mix IV } \\
\hline 1 & 2.3 & 2.1 & 3.1 & 2 & 9.5 \\
\hline 2 & 3.8 & 3.6 & 3.1 & 2.6 & 13.1 \\
\hline 3 & 3.3 & 2.1 & 3.2 & 2.6 & 11.2 \\
\hline 4 & 3 & 2.8 & 3 & 2.2 & 11 \\
\hline 5 & 3.4 & 2.6 & 4 & 3 & 13 \\
\hline 6 & 3.1 & 3.4 & 2.9 & 2.6 & 12 \\
\hline \multicolumn{6}{|c|}{ Health Mix V } \\
\hline 1 & 3.9 & 3.5 & 3.6 & 3.7 & 14.7 \\
\hline 2 & 3.7 & 3.6 & 3.6 & 3.7 & 14.6 \\
\hline 3 & 3 & 3 & 2.3 & 2.8 & 11.1 \\
\hline 4 & 2.1 & 2.9 & 2.9 & 2.5 & 11.4 \\
\hline 5 & 4.3 & 3.8 & 4.3 & 4.2 & 16.6 \\
\hline 6 & 2 & 2.9 & 1.9 & 3.6 & 10.4 \\
\hline
\end{tabular}

acceptability score of 14.7 out of the maximum score 20. Similarly variation 2 received the scores 3.7, 3.6, 3.6, 3.7 for the various characteristics with the overall acceptability score of 14.6. Variation 3 obtained 3, 3, 2.3, 2.8 for the characteristics with the overall acceptability score of 11.1 out of the maximum score of 20. Variation 4 obtained 2.1 for colour out of 5, 2.9 for flavour, 2.9 for texture and 2.5 for taste, with the maximum overall acceptability score of
11.4. Among the six, variations 5 and 6 received 4.3, 2 for colour; 3.8, 2.9 for flavour; 4.3, 1.9 for texture and $4.2,3.6$ for taste with the overall acceptability score of 16.6 and 10.4 respectively.

Ten panellists evaluated the thirty variations of health mixes. Among thirty variations, one variation which got the highest score from each type of health mix was selected and subjected to further analysis. 


\subsubsection{Overall Acceptability Scores of Health Mixes}

Table 8 presents the mean overall acceptability scores of health mixes.

Table 8. Overall acceptability scores of health mixes
Combination of foods by bacterial load and mould could result in unacceptable products [11]. Microbial count in the health mixes on storage (room temperature) was compared with the fresh formulations and the details are given in Table 10.

\begin{tabular}{|c|c|c|c|c|c|}
\hline Variations & Health Mix I & Health Mix II & Health Mix III & Health Mix IV & HealthMix V \\
\hline 1 & 11.7 & 11.6 & 11.6 & 9.5 & 14.7 \\
\hline 2 & 11.2 & 10.4 & 9.9 & $\mathbf{1 3 . 1}$ & 14.6 \\
\hline 3 & 14.4 & $\mathbf{1 4 . 1}$ & $\mathbf{1 3 . 4}$ & 11.2 & 11.1 \\
\hline 4 & $\mathbf{1 4 . 8}$ & 9.4 & 12.5 & 11 & 11.4 \\
\hline 5 & 14.0 & 12.3 & 11.7 & 13 & $\mathbf{1 6 . 6}$ \\
\hline 6 & 12 & 11.8 & 12.6 & 12 & 10.4 \\
\hline
\end{tabular}

When the overall acceptability of the scores of variations were compared for the five health mixes, variation 4 of health mix I, variation 3 of health mix II, variation 3 of health mix III, variation 2 of health mix IV and variation 5 of health mix $\mathrm{V}$ received the highest scores when compared with their respective counterparts. One variation from each health mix, which got the highest score was selected and subjected to moisture content and microbial assay.

\subsubsection{Shelf Life of the Health Mixes}

\subsubsection{Moisture Content and Peroxide Value of the Selected Five Variations}

Moisture content is a critical index for prevention of spoilage. Peroxide value indicates the lipid oxidation. The details regarding moisture content and peroxide value of the selected five variations are given in the fresh form and the sample preserved for ninety days (Table 9).

It was observed that there was an increase in the moisture content of all the five variations on storage. But the increase in the moisture content was within the safe levels (15.1 per cent) given by FAO/WHO [8]. The minimum gain in the moisture may be due to the use of low density polyethylene bags for storing [9]. Similarly the peroxide value in the five variations varied between 0.01 and $0.02 \mathrm{meq} / \mathrm{kg}$. On storage it increased slightly but was within the safe level suggested by $\mathrm{FAO} / \mathrm{WHO}[10]$, indicating that the health mixes did not undergo rancidity on storage for ninety days.

\subsubsection{Microbial Assay}

Table 9. Moisture content and peroxide value of the selected five variations

\begin{tabular}{|r|c|c|}
\hline VARIATIONS & $\begin{array}{c}\text { MOISTURE } \\
\text { (PERCENT) }\end{array}$ & $\begin{array}{c}\text { PEROXIDE VALUE } \\
\text { (meq/kg) }\end{array}$ \\
\hline HM I VAR 4 A & 5.82 & 0.010 \\
\hline B & 5.80 & 1.017 \\
\hline HM II VAR 3 A & 6.15 & 0.010 \\
\hline B & 6.19 & 0.013 \\
\hline HM III VAR 3 A & 5.19 & 0.010 \\
\hline B & 5.22 & 0.014 \\
\hline HM IV VAR 2 A & 5.55 & 0.020 \\
\hline B & 5.59 & 0.028 \\
\hline HM V VAR 5 A & 4.66 & 0.010 \\
\hline B & 4.71 & 0.050 \\
\hline
\end{tabular}

HM - Health Mix, VAR - Variation

A - Fresh Sample B - 90 days after storage

Table 10. Total bacterial count in the selected five variations

\begin{tabular}{|c|c|c|}
\hline \multirow{2}{*}{ Health Mixes } & \multicolumn{2}{|c|}{} \\
\cline { 2 - 3 } & Initial & Final \\
\hline HM I VAR 4 & 21000 & 23000 \\
\hline HM II VAR 3 & 19500 & 21000 \\
\hline HM III VAR 3 & 19000 & 22500 \\
\hline HM IV VAR 2 & 18500 & 21000 \\
\hline HM V VAR 5 & 17100 & 20500 \\
\hline
\end{tabular}


The bacterial count of fresh sample at dilution 10.3 ranged between 17100-21000 whereas in the three month old sample the count increased and ranged lower than the specified counts 30000-60000/g [12]. This shows that all the formulated food variations indicate that these variations retained desirable characteristics on storage for a period of three months. All the food formulations had a good shelf life and were found to be fit for consumption even after three months.

Among the best variations from each health mix, variation 5 of health mix $\mathrm{V}$ got the highest score of 16.6 in organoleptic evaluation because of its highest score in taste and colour, maximum nutrient content, minimum moisture content and peroxide value and with less total bacterial count. However based on the nutrient content and shelf life study, variation 5 of health mix V was adjudged to be the best and named as HEALTH PLUS and used for further nutrition intervention study. Health plus was formulated with ingredients namely wheat, soy flour, wheat germ, tomato, beetroot, sunflower seeds and jaggery in the ratio of 15:15:15:15:15:10:15. The fresh and powered immune boosters, modulators and regulators of health plus is given in Plates 8 and 9. Six variations formulated with variation 5 of health mix V is given in Plate 10 .

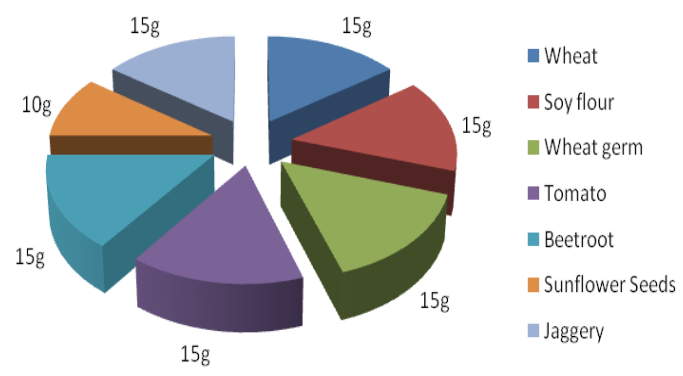

Figure 1. Proportion of health plus.

\subsubsection{Nutrient Content of Standarised Health Plus}

The nutrient content of standardized health plus is given in Tables 11.

Health plus was subjected to nutrient analysis using standard procedure. The moisture content of health plus was $9.9 \mathrm{~g} / 100 \mathrm{~g}$ of health mix. The energy content was $640 \mathrm{Kcal}$. Carbohydrate content was found to be $64.5 \mathrm{~g}$ and dietary fibre was $18.8 \mathrm{~g}$ in $100 \mathrm{~g}$ of
Table 11. Macronutrient content (per $100 \mathrm{~g}$ ) of health plus

\begin{tabular}{|l|c|}
\hline \multicolumn{1}{|c|}{ Macronutrients } & Health Plus \\
\hline Moisture (g) & 9.9 \\
\hline Ash (g) & 5.8 \\
\hline Energy(Kcal) & 640 \\
\hline Carbohydrates (g) & 64.5 \\
\hline Dietary fibre (g) & 18.8 \\
\hline Protein (g) & 23.3 \\
\hline Total fat (g) & 4.3 \\
\hline Saturated fat (g) & 0.6 \\
\hline Monounsaturated fat (mg) & 0.6 \\
\hline Polyunsaturated fat (mg) & 2.2 \\
\hline
\end{tabular}

health plus. Protein content was found to be 23.3g. Polyunsaturated fat content of the mix was $2.2 \mathrm{mg}$.

Table 12. Amino acids profile of health plus (per $100 \mathrm{~g}$ )

\begin{tabular}{|l|c|l|c|}
\hline \multicolumn{1}{|c|}{ Amino acids } & $\begin{array}{c}\text { Health } \\
\text { Plus }\end{array}$ & \multicolumn{1}{|c|}{ Amino acids } & $\begin{array}{c}\text { Health } \\
\text { Plus }\end{array}$ \\
\hline Histidine (mg) & 430 & Cystine (mg) & 371 \\
\hline Isoleucine (mg) & 486 & Tyrosine (mg) & 436 \\
\hline Lysine (mg) & 600 & Arginine (mg) & 1087 \\
\hline Leucine (mg) & 928 & Alanine (mg) & 765 \\
\hline Methionine (mg) & 24 & Aspartic acid (mg) & 1130 \\
\hline Phenylalanine (mg) & 595 & Glutamic acid (mg) & 2874 \\
\hline Threonine (mg) & 500 & Glycine (mg) & 898 \\
\hline Tryptophan (mg) & 282 & Proline (mg) & 882 \\
\hline Valine (mg) & 726 & Serine (mg) & 684 \\
\hline
\end{tabular}

Standardised health plus was assessed for its amino acid content using standard procedures. Hundred gram of health plus contains an appreciable amount of essential and non-essential amino acids. Histidine content of health plus was $430 \mathrm{mg}$ and isoleucine content was 480 $\mathrm{mg}$. Leucine content was $928 \mathrm{mgTryptophan}$ content of health plus was $282 \mathrm{mg}$. Threonine content was $500 \mathrm{mg}$. Methionine content of health plus was very minimum around $24 \mathrm{mg}$. The Phenylalanine content was found to be $595 \mathrm{mg}$ and valine content of health plus was $726 \mathrm{mg}$ A good ratio of non-essential amino acids which cannot be synthesised by the body was also present in 
health plus. Health plus contained $3874 \mathrm{mg}$ of glutamicacid. The formulated health plus contains a good ratio of essential to non essential amino acids. Cystine content of health plus was $371 \mathrm{mg}$ and tyrosine content was $436 \mathrm{mg}$. Health plus contained $1087 \mathrm{mg}$ of arginine.

Aspartic acid content of health plus was $1130 \mathrm{mg}$ and glutamic acid was $2874 \mathrm{mg}$. Glycine content of health plus was around $898 \mathrm{mg}$. Proline content was found to be $882 \mathrm{mg}$. Serine content of health plus was $684 \mathrm{mg}$.

\section{Conclusion}

The findings of the study revealed that the ingredients namely wheat, soy flour, wheat germ, tomato, beet root, sun flower seed and jaggery which are available at our doorsteps in affordable cost by the layman are foods rich in immune boosters, modulators and regulatory to improve the immune status of the HIV positive women.

\section{References}

1. Allard J. P., "Effects of multinutrient supplementation on oxidative stress and viral load in HIV-infected subjects", JAIDS-J. Acq. Imm. Def, vol. 12, p. 16-53, 2007.

2. Gorbach S. L., Knox T. A., Roubenoff R., "Interaction between nutrition and infection with Human Immunodeficiency Virus", Nutr Rev, vol. 51, p. 226-234, 1993.

3. Swaminathan M., Principles of Nutrition and Dietetics, 2nd edition, Bapco Publishing, Bangalore, p. 32, 2005.
4. Krishnaswamy A., "Prespective on nutrition needs for the twenty first century", XXXVI Annual Meet of Nutrition Society of India, p. 25-28, 2004.

5. Sherlekar S., Udipi S. A., "Role of nutrition in the management of HIV infection /AIDS", J. Indian Med. Assoc, vol. 100(6), p. 385-390, 2006.

6. Dabuja, S., and Kapoor, A. C. "Acceptability and viscosity of low cost home processed supplementary foods developed for pre school children", Plant Food Hum. Nutr, 46(4), p. 287-2, 2004.

7. NIN - Pre conference workshop on epidemiological looks in assessment of Nutrition status, Hyderabad; Nutrition society of India, Indian council of medical research, Jamai, Osmania, p. 6-9, 1983.

8. FAO/WHO, "Food standard programme codex alimentaries commission. Codex alimentaries-fats and oil and related products", 2nd edition, p. 13, 2005.

9. Balasubramaniam N., and Anandhaswamy B., "Packaging requirement of convenience foods", Paper presented at Seminar on Convenience Foods-Opportunities and Challenges, Dec 21/22, Mumbai, p. 22, 2008.

10. FAO/WHO, "New manual for people living with HIV/ AIDS, Feeding hope: Nutrition plays key role in HIV/AIDS care", p. 1, 2003.

11. Ranganna S., "Sensory Evaluation-General instruction for microbiological examination" Hand Book of Analysis and Quality Control, 2nd edition, Tata Mc Grawhik, Hill Publishing Co, New Delhi, p. 168-169, 2006.

12. Regai M. K., Microbial Examination of Foods, Manual of Food Quality Control and Microbial Analysis, FAO publication, Rome, p. 4, 17, 2009. 